\title{
Possíveis conexões entre o relato autobiográfico e a formação docente a partir da ótica dos coordenadores pedagógicos ${ }^{1}$ Possible connections between the autobiographical report and the teacher training from the pedagogic coordinators perspective
}

\author{
Osmar Hélio Alves Araújo \\ Universidade Regional do Cariri (Urca), Cariri (CE) - Brasil \\ Célia de Jesus Silva Magalhães \\ Universidade Regional do Cariri (Urca), Cariri (CE) - Brasil
}

\begin{abstract}
Resumo
O relato autobiográfico é um instrumento formativo no processo de qualificação docente. Esta pesquisa investigou como o coordenador pedagógico insere o relato autobiográfico na formação contínua do professor no contexto escolar como um elemento formativo. A pesquisa empírica envolveu dois coordenadores pedagógicos de duas instituições públicas de ensino fundamental da rede pública de ensino do município de Missão Velha (CE). Para a coleta de dados, foram aplicadas duas entrevistas semiestruturadas. Os resultados evidenciam fragilidades que permeiam o processo de formação de educadores em relação ao liame entre a formação e a história de vida do professor, pois a história de vida do professor não foi referendada, nem mesmo apontada como categoria a ser explorada em sua formação.
\end{abstract}

Palavras-chave: Relato autobiográfico, Formação docente, Coordenador pedagógico

\begin{abstract}
The self-biographical report is a training tool in the qualification process of teachers. We have investigated how the pedagogical coordinator inserts the self-biographical report in the continuous teacher training in the school context as a formative element. The empirical research has involved two pedagogical coordinators from two public primary schools of the Missão Velha city in Ceará state. For data collection, we have applied two semi-structured interviews. The results show fragilities permeating the teacher training process in relation to the connection between the training and the teacher life story, because the teacher life story has not been countersigned nor even pointed out as a category to be explored in the training.
\end{abstract}

Keywords: Self-biographical report, Teacher training, Pedagogical coordinator

\footnotetext{
${ }^{1}$ Este texto teve como solo embrionário a disciplina de Educação, Currículo e Ensino, do Programa de Pós-Graduação em Educação, Universidade Federal do Ceará - UFC, sob a coordenação do professor dr. Luiz Botelho Albuquerque e do prof. dr. Henrique Sérgio Beltrão de Castro. Os autores agradecem aos professores pelas contribuições na concepção deste texto.
}

Revista Educação Online Rio de Janeiro, n. 22, mai-ago 2016, p. 82-88 


\section{Introdução}

Compreende-se que a história de vida do professor e seu processo de formação, por meio do relato autobiográfico, podem ser entrelaçados e se constituírem em um instrumento de qualificação docente, pois permitem ao professor refletir a partir das experiências, pessoais e profissionais, e de seu percurso formativo, ampliando e teorizando as aprendizagens alcançadas. Por isso, o relato autobiográfico é carregado de significado que vai além do simples fato de reconstruir a própria história docente. A narrativa autobiográfica é texto, discurso, narrativa que oportuniza reflexão e a partir da qual se forja a identidade docente.

No rastro do exposto, realça-se a pujança da inserção da história de vida do professor, por meio da autobiografia, nas práticas de formação docente, como um território que lhe permite intercruzar e teorizar as experiências e saberes, discutir e aprofundar questões imbricadas na sua prática pedagógica. Nesse sentido, perfilouse como objetivo investigar como o coordenador pedagógico insere o relato autobiográfico na formação contínua do professor no contexto escolar como um elemento formativo.

Resumidamente, verificou-se que o relato autobiográfico é inserido na formação contínua do professor na esfera escolar, de modo pontual e insuficiente, pois os coordenadores pedagógicos manifestaram dificuldades no que tange à compreensão do referido instrumento como uma atividade formativa e que, portanto, permite ao professor trazer à tona suas experiências e descobertas profissionais, história de vida e trajetória de formação. Em suma, os dados levantados concorreram para evidenciar fragilidades que permeiam o processo de formação docente, em relação ao liame entre a formação e a história de vida do professor, pois são elementos imbricados na formação docente, como a história de vida do professor; foram pouco referendados e mesmo reconhecidos como pontos a serem explorados na formação dos professores.

\section{Caminho metodológico}

A paisagem desta investigação foi o contexto de duas instituições públicas de ensino fundamental da rede pública do Ceará, especificamente do município de Missão Velha/CE. Quanto aos sujeitos da investigação, foi oportuno trabalhar com duas coordenadoras pedagógicas, integrantes do núcleo gestor das referidas 
instituições, os quais foram denominados aqui de coordenadoras pedagógicas $A$ e $B^{2}$. Essas coordenadoras são vinculadas à Secretaria de Educação do município de Missão velha/CE. Optou-se pelas referidas profissionais por apresentarem mais de três anos de experiência correlata à gestão escolar, coordenação pedagógica, assim como mais de oito anos de exercício no magistério.

Para a coleta de dados, aplicou-se uma entrevista semiestruturada, cujas questões visaram a investigar a existência de formação contínua para os professores no contexto escolar, a relação que é estabelecida entre a história de vida dos professores e seu processo de formação contínua e averiguar a compreensão dos coordenadores pedagógicos em relação à importância do relato autobiográfico na formação docente.

O que texto que segue traz à tona os dados colhidos, fundamentados a partir das contribuições de alguns autores, entre eles Formenti (2008); Araújo (2015); Nóvoa (2009), que fortaleceram a discussão.

\section{Análise e discussão dos resultados}

O relato autobiográfico permite ao professor estabelecer relações entre as aprendizagens emergidas dos territórios de atuação, acessar, a sua trajetória de profissionalização docente, assim como aprofundar questões teórico-metodológicas enredadas às práticas pedagógicas. Nessa perspectiva, o coordenador pedagógico deve cruzar, no processo de formação docente, sob profundos questionamentos, as histórias de vida dos professores, atitudes e comportamentos, e sua existência docente, visando a romper com moldes escolares pré-determinados e, como desdobramento, fazendo emergir transformações nas práticas pedagógicas. Como sustenta Nóvoa (2009), é necessário dedicar uma atenção especial às dimensões pessoais da profissão docente na formação de professores.

É necessário esclarecer, a priori, que a ação efetiva do relato autobiográfico é o escrever, porém, pode-se recorrer a outros modos, bem como de diversas linguagens (FORMENTI, 2008). Entretanto, deve ser abalizado por reflexões metodológicas e epistemológicas capazes de desencadearem um processo de formação. Formenti (2008) assinala que, por meio da narração autobiográfica, o sujeito se torna um pesquisador em busca de compreender o viver e o próprio saber.

2 Os respectivos pseudônimos foram alçados a partir do questionário aplicado com cada coordenador. Revista Educação Online Rio de Janeiro, n. 22, mai-ago 2016, p. 82-88 
É nessa direção que essa discussão traz à baila a necessidade da inserção do relato autobiográfico na formação docente, como um instrumento formativo que permite ao professor estabelecer conexão entre os saberes, identidade docente e experiências.

Como assinalou Nóvoa (2009), é preciso estimular, junto à população docente, a construção de narrativas sobre as suas próprias histórias de vida pessoal e profissional, pois, como realça o autor, esse esforço é essencial para se compreender a especificidade da profissão docente e para que os professores construam percursos significativos de aprendizagem ao longo da vida. Por essa razão, cabe ao coordenador pedagógico inserir o relato autobiográfico no processo de formação docente desenvolvido a partir da arena escolar, o que permitirá ao professor viver, ou até mesmo desvelar, a sua história, experiência e descoberta profissional, assim como os saberes contidos e latentes, porém, muitas vezes, desconhecidos ou inconscientes, na sua prática pedagógica.

O conhecimento é proveniente da trajetória pessoal e profissional de cada indivíduo, entretanto, nem sempre os coordenadores pedagógicos estabelecem a relação necessária entre a história de vida do professor e seu processo de formação profissional. O depoimento da coordenadora A corrobora essa assertiva, pois segundo ela, "Nós não conseguimos fazer essa relação entre a história de vida do professor e seu professor de formação contínua". Já a coordenadora B expõe que "Existem professores que não buscam aprender, assim como não procuram participar das formações dentro ou fora da escola. Alguns deles não gostam de participar nos planejamentos realizados na escola, preferem fazer (o planejamento) em casa".

A partir dos depoimentos, é possível considerar que, provavelmente, as histórias de vida dos professores são tomadas como histórias simplistas e entorpecidas por formações pautadas nos conteúdos escolares, currículo como um conjunto de conteúdos, resultados de avaliações externas ${ }^{3}$, entre outros, que apequenam as histórias de vida dos professores e descaracterizam o real sentido da formação docente a partir da escola, pois, sobre os conteúdos que norteiam a formação docente na esfera escolar, a coordenadora pedagógica A ressalta que:

Na nossa escola, nós trabalhamos com os planejamentos semanais que são aquelas janelas do ensino fundamental II. Nós também trabalhamos com o planejamento

\footnotetext{
${ }^{3}$ Freitas (2014) adverte que as avaliações externas vêm ocupando historicamente um lugar central na escola atual, contribuindo, assim, para a padronização e o esvaziamento da ação pedagógica.
}

Revista Educação Online Rio de Janeiro, n. 22, mai-ago 2016, p. 82-88 
mensal, mensalmente nós fazemos o planejamento. Nós temos também o Pnaic ${ }^{4}$ e o Paic $^{5}$, que é em relação ao português e à matemática. Sempre nos planejamentos, nós escolhemos um tema, pois os professores falam suas dificuldades de trabalharem na sala de aula e sempre trazemos uma pessoa que faz uma palestra e conversa com os professores a respeito do tema escolhido, como a inclusão social que estava agendada, pois algumas pessoas estavam com dificuldades nesta área. O Paic e o Pnaic já vêm às datas agendadas, as rotinas pela secretaria de educação e o material de cada área para cada professor.

Visando a atribuir sentido e significado ao quadro apontado pela coordenadora pedagógica, sugere-se aqui que o processo de formação docente, mediado pelo coordenador pedagógico, seja construído também pelas múltiplas histórias docentes que constituem a diversidade de saberes do território escolar. Por conseguinte, que o trabalho com o relato autobiográfico na formação docente seja um dispositivo formativo, que faça eclodir reflexões a partir da trajetória pessoal e profissional de cada professor, pois todo o seu percurso pessoal e profissional aloja heranças pedagógicas, crenças, questionamentos, rupturas e projetos de vida, além de experiências e aprendizagens. Isso traz à tona a importância da dimensão pessoal do professor no seu processo de formação.

A respeito da formação docente a partir da escola, uma importante explicação é fornecida por Araújo (2015, p. 64). O referido autor enfatiza que "o contexto escolar é uma arena fértil para a formação contínua dos professores, cujas ações pedagógicas devem confluir para a materialização do aludido processo". O autor argumenta ainda que cabe aos coordenadores pedagógicos materializarem um processo de formação docente, visando a instigar nos professores uma postura investigativa, crítica-reflexiva, transformando a sala de aula em laboratório de formação, investigação.

O trabalho com a história de vida do professor em seu processo de formação permite, portanto, caracterizá-lo como sujeito de história peculiar, ao mesmo tempo coletiva, assim como compreendê-lo como um sujeito em desenvolvimento pessoal e

\footnotetext{
4 O Pacto Nacional pela Alfabetização na Idade Certa/Pnaic é um compromisso formal assumido pelos governos federal, do distrito federal, dos estados e municípios de assegurar que todas as crianças estejam alfabetizadas até os oito anos de idade, ao final do $3^{\circ}$ ano do ensino fundamental. Disponível em: <http://pacto.mec.gov.br/o-pacto>. Acesso em: 12/03/2016.

${ }^{5}$ Programa Alfabetização na Idade Certa - Paic é um programa de cooperação entre Governo do Estado e municípios cearenses com a finalidade de apoiar os municípios para alfabetizar os alunos da rede pública de ensino até o final do segundo ano do ensino fundamental. Disponível em: <http://www.paic.seduc.ce.gov.br/index.php/o-paic/historico/historia>. Acesso em: 12/03/2016.
}

Revista Educação Online Rio de Janeiro, n. 22, mai-ago 2016, p. 82-88 
profissional contínuo. Logo, é oportuno que o coordenador pedagógico desperte no professor a consciência da necessidade de se assumir como autor/ator da sua história, mediante um fazer pedagógico autônomo, assim como se perceber como um sujeito docente, aprendiz da profissão e produto de uma história docente inacabada, pois, "por mais que uma história tenha sido bem escrita e bem pensada, não será nunca definitiva" (FORMENTI, 2008, p.55). Por essa razão, cabe aos coordenadores pedagógicos, materializarem atividades formativas que possibilitem aos professores valorizarem e atribuírem sentido às aprendizagens e experiências, bem como se tornarem cônscios das potencialidades, intencionalidades e projeto de vida.

Face ao exposto, a narrativa (auto)biográfica une, com âncora em uma abordagem qualitativa, as diversas facetas que compõem o processo pessoal e profissional do professor, constituindo-se, assim, como um importante aparato formativo docente. Nesse sentido, as declarações das coordenadoras pedagógicas confluem para o enaltecimento do relato (auto)biográfico, uma vez que assinalam que: "o relato (auto)biográfico é importante, pois possibilitam planejar melhor as formações dos professores" (COORDENADORA A). A coordenadora B entende que:

É necessário que conheçamos nossos professores, para que possamos ajudá-los. Por meio de pesquisas que exploram a importância da narrativa autobiográfica descobrimos que, na verdade, não conhecemos, a fundo, as histórias de vida dos nossos professores, apenas arquivamos seus diplomas e não conversamos com os docentes sobre eles.

Sobre a pesquisa, a inserção do relato (auto)biográfico na formação docente na perspectiva dos coordenadores pedagógicos, a mesma coordenadora pontua que

O que achei interessante nessa pesquisa é que nos despertou para essa área que nós, como coordenadores, muitas vezes, deixamos passar despercebido que é a vida, a história de vida do professor; muitas vezes nos detemos nos diplomas que eles trazem, arquivamos na escola e não há essa conversação com eles sobre os anseios, as expectativas, nos detemos em seus diplomas.

A pertinência deste estudo, a partir da declaração da coordenadora pedagógica, possivelmente, trouxe aos pesquisadores o sentimento de que valeu a pena o esforço empreendido, pois, como sustenta Freire (1996, p. 39), "o ato de refletir é libertador porque instrumentaliza o educador no que ele tem de mais vital: o seu pensar". Por fim, espera-se que os coordenadores pedagógicos, por meio da inserção do relato autobiográfico na formação contínua do professor, possibilitem 
aos professores refletir sobre o fazer pedagógico, experiências e aprendizagens e fortaleça o pensamento crítico e construtivo, a fim de imprimir marcas no mundo.

\section{Considerações finais}

A discussão aqui empreendida aponta para a necessidade da inserção do relato autobiográfico na formação docente como um instrumento com fecundidade formativa de investigação, de transformação do ser e exercer a docência, pois o referido instrumento, abalizado em uma perspectiva holística, desdobra-se em narrativas reflexivas, autoformativas, assim como autoavaliativas.

São inúmeras as aprendizagens que se interiorizam na trajetória pessoal e profissional do professor, e, em face disso, o relato autobiográfico permite ao professor a tomada de consciência de suas realidades, possibilidades de mudanças, atitudes e comportamentos, ou seja, oportuniza ao professor, à medida que cria e recria a própria história, transformar-se, reagrupar conhecimentos e se existenciar.

\section{Referências bibliográficas}

ARAÚJO, Osmar Hélio Alves. Formação docente, professor coordenador pedagógico e contexto escolar: diálogos possíveis. Dissertação (Mestrado em Educação) - Faculdade de Educação, Universidade Federal do Ceará. Fortaleza, 2015.

NÓVOA, Antonio. Professores: imagens do futuro presente. Lisboa: EDUCA, 2009.

FREITAS, Luiz Carlos de. Os reformadores empresariais da educação e a disputa pelo controle do processo pedagógico na escola. Educ. Soc., v.35, n.129, p. 10851114, out-dez 2014. Disponível em: <http://www.scielo.br/pdf/es/v35n129/01017330-es-35-129-01085.pdf>. Acesso em: 23/03/ 2016.

FREIRE, Madalena. Observação, registro, reflexão - instrumentos metodológicos I. 2aed. Local de publicação: Espaço Pedagógico, 1996. (Série Seminários)

FORMENTI, Laura. Escrita autobiográfica e zelo: um olhar composicional. In: PASSEGGI, Maria da Conceição (Org.). Tendências da pesquisa (auto)biográfica. Natal; São Paulo: EDUFRN; Paulus, 2008. p. 50-71. (Coleção Pesquisa (Auto) Biográfica - Educação). 